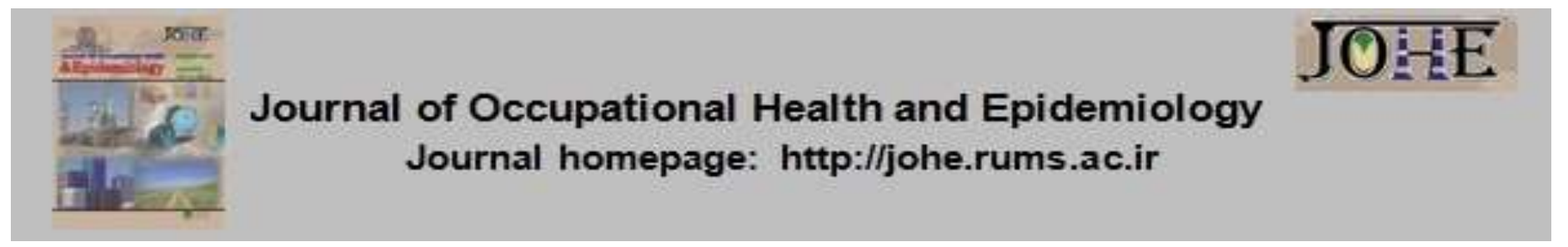

\title{
An Evaluation of the Health-Promoting Lifestyle and Quality of Life among Turkish Workers, 2017
}

\author{
Özlem Terzi ${ }^{1}$, Özge Karasu², H. Nilden Arslan ${ }^{1}$ \\ 1- Assistant Prof., Dept. of Public Health, Faculty of Medicine, Ondokuz Mayis University, Samsun, Turkey. \\ 2- Workplace Physician, MD, Samsun Provincial Directorate of Health, Samsun, Turkey.
}

\section{Article Info}

* Corresponding author:

Özlem Terzi,

E-mail:

ozlem.terzi@omu.edu.tr

\section{Article history}

Received: Jan 2020

Accepted: Jun 2020

10.29252/johe.9.1.10

Print ISSN: 2251-8096 Online ISSN: 2252-0902

Peer review under responsibility of Journal of Occupational Health and Epidemiology
Citation: Terzi Ö, Karasu Ö, Arslan N. An Evaluation of the Health-Promoting Lifestyle and

Quality of Life among Turkish Workers, 2017. JOHE 2020; 9(1):10-7.

\begin{abstract}
Background: The examination of workers' health behaviors and their quality of life, as well as providing support in missing areas are important in terms of both occupational health and community health. This study aims to assess workers' quality of life and health-promoting lifestyle in a workplace in 2017 and to determine their relationship with some socio-demographic characteristics.

Material and Methods: This descriptive study was conducted from January to March 2017 in Samsun province. A total of 151 workers participated in the study. The data were collected using a questionnaire on workers' socio-demographic characteristics, HealthPromoting Lifestyle Profile II (HPLP II), and Short Form-36 Quality of Life Scale (SF-36). The mean values were compared using Kruskal-Wallis and Mann-Whitney $U$ tests. The correlation was evaluated using Spearman's correlation analysis. In addition, p-value $0<0.05$ was considered statistically significant.

Results: The workers had an average of $132.48 \pm 23.65$ points on the HPL profile. In addition, HPL scores were significantly higher in the older age group $(p<0.05)$. However, there was no difference in terms of other socio-demographic characteristics $(p>0.05)$. Besides, there was a positive and low level significant correlation between the workers' HPL scale scores and only four subscales of SF $36(p<0.05)$.

Conclusion: According to the result of this study, the workers' health-related quality of life was found to be below the Turkish community standards, with the workers' healthy lifestyle behavior having been moderate. In addition, some sociodemographic characteristics had a negligible effect on the quality of life, and healthy lifestyle behaviors positively increased employees' quality of life.
\end{abstract}

Keywords: Employees, Workers, Quality of Life, Turkey

\section{Introduction}

Today, according to a health perception, protecting, sustaining, and improving health among individuals, families, and communities are of high importance. Accordingly, showing behaviors to protect, maintain, and improve wellness among individuals and to make correct decisions about self-health is of great significance [1-3]. Healthpromoting behaviors aim to increase the level of well-being and to promote self-improvement. A 'healthy lifestyle' is identified as a lifestyle that controls all behaviors affecting an individual's health, which chooses the correct behaviors appropriate for their health in daily activities. Healthy lifestyle behaviors include adequate and regular exercise, a balanced diet, a non-smoking approach, health responsibilities, stress management, and hygienic measures [3-4].

Lifestyle affects both the quality of life and the life span. The causes of $70-80 \%$ and $40-50 \%$ of deaths in developed countries and in lessdeveloped countries, respectively, are lifestyle- 
related diseases. Instead of infectious diseases that were common causes of mortality in the past, chronic lifestyle-related diseases, such as hypertension, obesity, type 2 diabetes, and coronary vascular disease (CVD) are observed more often today. A cross-sectional study showed that overweight workers and physically inactive workers were by 1.5 and 1.3 times more likely to be at the risk of CVD, respectively. This finding is supported by the relationship between the CVD risk as well as overweight and/or physical inactivity, with overweight having been specified as a major CVD risk factor [5]. Accordingly, measures that change the lifestyle are considered as the most effective factor in protection against diseases and an improvement in health [6].

The quality of life is another factor affected by an individual's lifestyle. The World Health Organization (WHO) states that individuals, apart from having to be productive in social, economic, and psychological settings, have to be healthy and have a better quality of life [7]. Occupational and employee health is one of the fields in which this concept has been attracting a great deal of attention [8]. With an improvement in healthy lifestyles along with a reduction in health risks and an increase in the quality of life among workers, improvements have been achieved in terms of associated economic and productivity factors, such as compensation payments, absenteeism, and job satisfaction [9]. According to a meta-analysis, poor health, particularly self-perceived poor health, is a risk factor for quitting paid employment through disability support pension, unemployment and to a lesser extent, early retirement [10]. Therefore, workplace health development programs have recently taken on an added importance [8].

Being healthy is a basic right, yet ensuring and maintaining it are the responsibility of individuals themselves as well as the health staff. Individuals must be willing to display positive health behaviors and to sustain them to ensure their own health [1, 2]. Thus, analyzing workers' health behaviors and life qualities in different jobs as well as supporting them in deficient aspects matter in terms of social and work health.

In this study, we aim to analyze the workers' quality of life and health-promoting lifestyle behaviors and to determine their correlation with some of their sociodemographic features in the central warehouse of a large chain of grocery stores.

\section{Materials and Methods}

This study is a descriptive cross-sectional study conducted from January to March 2017 in Samsun province, where Turkey enjoys a moderate socioeconomic development. To conduct this research, approval was received from the Clinical Research Ethics Committee of Ondokuz Mayıs University on 13/01/2017 under ethics code 678. All employees of the central warehouse of a large chain of grocery stores, including warehouse workers, office workers, service workers (i.e. cooks, dishwashers, and drivers), as well as distribution workers formed the research sample $(\mathrm{N}=181)$. In other words, all employees were included in this study. No sampling was conducted in this research. The selection criteria included being accepted as a warehouse worker, being over 18 years old, and being a volunteer in this study. Non-volunteers and those under the age of 18 were excluded from the study. The study objectives were explained to the employees by the researchers, and questionnaires were distributed among the volunteers. On the same day, survey results were collected by the researchers. Those individuals who could not be contacted due to shiftwork conditions were visited again on the next day. Under the same conditions, the questionnaires were distributed and collected. A total of 151 $(83.4 \%)$ workers agreed to participate in this study. Data were collected using a questionnaire containing the workers' sociodemographic characteristics, Health-Promoting Lifestyle (HPL) Profile II, and Short Form-36 Quality of Life Scale (SF-36).

The Health-Promoting Lifestyle Profile (HPLP) was developed by Walker et al to measure health behaviors in individuals [11]. The scale was revised in 1996 and called HPLP II [12]. This scale was adapted to Turkey by Esin [3]. The scale is Likert-type and consists of 52 items and six factors, with all expressions evaluated. Each item is given one of the points 1 (never), 2 (sometimes), 3 (often), and 4 (regularly). The alpha reliability coefficient of the scale ranges from 0.79 to 0.94 . In addition, the lowest and highest scores are 52 and 208, respectively. There are six subscales for this scale, including self-actualization, health responsibility, exercise habits, nutrition habits, interpersonal support, and stress management. The questionnaire was used to measure healthpromoting behaviors associated with the individual's healthy lifestyle. High scores on the scale indicated that the individual exhibited specified health-related behaviors at a high level. The sub-assessment scores of the scale could be used separately or as a total score $[3,11]$. The total score of the HPL scale was used in this study. The SF-36 quality of life scale was developed by Ware et al (1987) [13]. Next, Koçyiğit et al (1999) verified its validity and reliability in Turkey [14]. 
This 36-expression scale evaluates three main headings and eight subscales associated with health concepts. These subscales include physical functioning, role limitations due to physical problems, pain, general health, energy/life/vitality, social functioning, and emotional state (as affected by emotional problems). On the SF-36 scale, scores range from 0 to 100 for each component. Accordingly, high scores for each subscale indicate a higher level of health, whereas low scores indicate health impairments [14].

The data obtained in this study were evaluated using SPSS V.15.0. The data for continuous variables were expressed as mean \pm standard deviation, the median (the maximum-minimum value), and the categorical value (\%). The normal distribution of the data was examined using the Kolmogorov-Smirnov $Z$ test. In addition, the correlation between HPL and SF-36 was assessed using Kruskal-Wallis and Mann-Whitney $U$ tests because the results of HPL and SF-36 did not fit the normal distribution. The correlation between HPL and SF-36 subscales was evaluated using Spearman's correlation analysis. The power of correlation would be considered weak if $r=0.00$ 0.24 , medium if $r=0.25-0.49$, strong if $r=0.50-0.74$, and very strong if $r=1.00$. In all statistical analyses, the results were considered statistically significant with $\mathrm{p}<0.05$.

\section{Results}

The mean age of the workers who participated in this study was $31.4 \pm 6.9$ ( $\min : 22$, max: 48 years), and $86.8 \%$ of them were male. As many as $37.7 \%$ of the participants were high school graduates, and $51 \%$ were married. Besides, $70.2 \%$ were warehouse workers, and $49 \%$ of all workers had been working in this warehouse for 1-5 years (Table 1).

Table 1. The workers' sociodemographic characteristics

\begin{tabular}{|c|c|c|}
\hline \multicolumn{2}{|c|}{ Variables } & n (\%) \\
\hline \multirow{2}{*}{ Gender } & Female & $20(13.2)$ \\
\hline & Male & $131(86.8)$ \\
\hline \multirow{3}{*}{ Age group (years) } & $20-29$ & $69(45.7)$ \\
\hline & $30-39$ & $61(40.4)$ \\
\hline & $40-49$ & $21(13.9)$ \\
\hline \multirow{4}{*}{ Educational level } & Primary school graduate & $18(11.9)$ \\
\hline & Secondary school graduate & $38(25.2)$ \\
\hline & High school graduate & $57(37.7)$ \\
\hline & Licensed graduate & $38(25.2)$ \\
\hline \multirow{2}{*}{ Marital status } & Married & $77(51.0)$ \\
\hline & Single & $74(49.0)$ \\
\hline \multirow{4}{*}{ Work field } & Distribution & $9(6.0)$ \\
\hline & Service & $13(8.6)$ \\
\hline & Office & $23(15.2)$ \\
\hline & Warehouse & $106(70.2)$ \\
\hline \multirow{3}{*}{ Work experience (months) } & $0-12$ & $58(38.4)$ \\
\hline & 13- 60 & $74(49.0)$ \\
\hline & $61+$ & $19(12.6)$ \\
\hline
\end{tabular}

The mean score the workers achieved on the HPL profile scale was $132.48 \pm 23.65$ (median: 132; min: 78; max: 183). The highest score of the life quality SF-36 scale was $80.62 \pm 30.84$ which was associated with the physical role difficulty (PRD); in contrast, the lowest score was $47.70 \pm 13.85$ on the mental health $(\mathrm{MH})$ subscale. Table 2 shows the scores for HPL and SF-36 subscales.

Table 2. Scores for the workers' health promotion lifestyle (HPL) and life quality subscales (SF-36)

\begin{tabular}{ccc}
\hline Variables & Mean (SD) & Median (Min-Max) \\
\hline Total HPL & $132.48(23.65)$ & $132(78-183)$ \\
\hline Physical Function (PF) & $76.58(19.25)$ & $80.0(20-100)$ \\
\hline Physical Role Difficulty (PRD) & $80.62(30.84)$ & $100(0-100)$ \\
\hline Pain (P) & $71.15(24.94)$ & $77.5(0-100)$ \\
\hline General Health Perception (GHP) & $52.81(9.75)$ & $55.0(35-75)$ \\
\hline Energy/Life/Vitality (ELV) & $75.18(11.61)$ & $60.0(20-80)$ \\
\hline Social Functionality (SF) & $64.32(24.80)$ & $62.5(0-100)$ \\
\hline Emotional Role Difficulty (ERD) & $77.70(32.13)$ & $100(0-100)$ \\
\hline Mental Health (MH) & $47.70(13.85)$ & $44.0(20-84)$
\end{tabular}


HPLP scores were lower in the workers aged 2029 than in other age categories, and this difference was statistically significant. However, there was no difference in the scores for the health promotion lifestyle scale in terms of other features $(p>0.05)$ (Table 3).

Table 3. An evaluation of the workers' health promotion lifestyle (HPL) scores in terms of sociodemographic data

\begin{tabular}{|c|c|c|c|}
\hline \multicolumn{2}{|c|}{ Variables } & \multirow{3}{*}{$\begin{array}{c}\text { Median (Min-Max) } \\
123(96-148) \\
132(78-183)\end{array}$} & \multirow{3}{*}{$\frac{\text { P-value }}{0.13}$} \\
\hline Gender & Female & & \\
\hline Gender & Male & & \\
\hline \multirow{3}{*}{ Age (years) } & $20-29$ & $124(78-156)$ & \multirow{3}{*}{0.002} \\
\hline & 30-39 & $139(86-183)$ & \\
\hline & $40-49$ & 144 (103-183) & \\
\hline \multirow{4}{*}{ Educational status } & Primary school graduate & $141(96-167)$ & \multirow{4}{*}{0.14} \\
\hline & Secondary school graduate & $124(78-173)$ & \\
\hline & High school graduate & $132(86-183)$ & \\
\hline & Licensed graduate & $141(112-181)$ & \\
\hline \multirow{2}{*}{ Marital status } & Married & $132(78-183)$ & \multirow{2}{*}{0.65} \\
\hline & Single & $132(100-181)$ & \\
\hline \multirow{4}{*}{ Work field } & Distribution & $126(101-148)$ & \multirow{4}{*}{0.18} \\
\hline & Service & $134(112-181)$ & \\
\hline & Office & $119(96-148)$ & \\
\hline & Warehouse & $133.5(78-183)$ & \\
\hline \multirow{3}{*}{$\begin{array}{l}\text { Work experience } \\
\text { (months) }\end{array}$} & $0-12$ & $132(90-183)$ & \multirow{3}{*}{0.88} \\
\hline & 13-60 & $135(86-178)$ & \\
\hline & $61+$ & $132(78-148)$ & \\
\hline
\end{tabular}

Table 4 shows the evaluation results of the life quality SF-36 subscale, including sex, age range, education, marital status, working area, and work experience for all workers. The physical functioning (PF) subscale showed a statistically significant difference only in terms of the age groups, which had the lowest values in workers aged $40-49(p<0.05)$. Although the PRD subscale score was significantly lower in workers aged 40$49(p<0.05)$, there was no difference between the median scores in terms of other demographic variables. Similarly, there was no difference among the groups in terms of the variables of pain $(P)$ and emotional role difficulty (ERD). The score of the general health perception (GHP) subscale was significantly lower in the single workers than in the married ones $(p<0.05)$. Although the scores of the energy/life/viability (ELV) subscale were slightly higher in the primary school graduates than in the secondary school graduates, they had significantly higher scores than the workers of other educational status $(p<0.05)$. Social functionality (SF) scores in the workers aged 20-29 were significantly lower than in the workers aged 40-49 $(p<0.05)$. However, there was no difference among other variables in terms of SF. While also mental health $(\mathrm{MH})$ subscale was higher in the 20-29 age group than in other age groups; it was significantly lower in the married workers who were primary school graduates than in the single workers with other educational status. (Table 4). However, there were no significant differences in the quality of life sub-scores among the workers in terms of the work field and work experience ( $p>0.05)$.

Table 4. An evaluation of the workers' life quality subscale scores according to sociodemographic data

\begin{tabular}{|c|c|c|c|c|c|c|c|c|}
\hline & PF & PRD & $\mathbf{P}$ & GHP & ELV & SF & ERD & $\mathrm{MH}$ \\
\hline \multicolumn{9}{|c|}{ Median } \\
\hline Gender & $p=0.5$ & $p=0.99$ & $\mathrm{p}=0.23$ & $\mathrm{p}=0.69$ & $p=0.07$ & $p=0.07$ & $\mathrm{p}=0.5$ & $\mathrm{p}=0.9$ \\
\hline Female & 82.5 & 100.0 & 77.5 & 50.0 & 55.0 & 50.0 & 83.3 & 44.0 \\
\hline Male & 80.0 & 100.0 & 77.5 & 55.0 & 60.0 & 62.5 & 100.0 & 44.0 \\
\hline Age range & $\mathrm{p}=0.02$ & $p=0.00$ & $\mathrm{p}=0.73$ & $p=0.56$ & $p=0.28$ & $\mathrm{p}=0.01$ & $\mathrm{p}=0.12$ & $\mathrm{p}<0.001$ \\
\hline $20-29$ & 80.0 & 100.0 & 77.5 & 50.0 & 60.0 & 62.5 & 100.0 & 48.0 \\
\hline $30-39$ & 85.0 & 100.0 & 77.5 & 55.0 & 55.0 & 75.0 & 100.0 & 44.0 \\
\hline $40-49$ & 75.0 & 75.0 & 77.5 & 55.0 & 60.0 & 87.5 & 100.0 & 44.0 \\
\hline Educational status & $\mathrm{p}=0.88$ & $\mathrm{p}=0.56$ & $\mathrm{p}=0.26$ & $\mathrm{p}=0.10$ & $p=0.00$ & $\mathrm{p}=0.76$ & $\mathrm{p}=0.08$ & $p=0.03$ \\
\hline Primary & 85.0 & 100.0 & 77.5 & 50.0 & 67.5 & 68,75 & 66.6 & 36.0 \\
\hline Secondary & 75.0 & 100.0 & 77.5 & 55.0 & 60.0 & 68.75 & 100.0 & 48.0 \\
\hline High school & 80.0 & 100.0 & 77.5 & 55.0 & 55.0 & 75.0 & 100.0 & 44.0 \\
\hline License & 75.0 & 100.0 & 79.5 & 55.0 & 55.5 & 62.5 & 83.3 & 44.0 \\
\hline Marital status & $p=0.19$ & $p=0.47$ & $\mathrm{p}=0.15$ & $p=0.03$ & $p=0.32$ & $p=0.2$ & $\mathrm{p}=0.68$ & $\mathrm{p}<0.001$ \\
\hline Married & 80.0 & 100.0 & 77.5 & 55.0 & 60.0 & 62.5 & 100.0 & 44.0 \\
\hline Single & 77,5 & 100.0 & 77.5 & 50.0 & 60.0 & 62.5 & 100.0 & 48.0 \\
\hline
\end{tabular}


Upon the evaluation of the correlation between HPL and SF-36 subscales, a low positive correlation was found between health HPL scores and only four of the SF-36 subscales, i.e. PF ( $r: 0.24, p: 0.003)$, PRD (r:0.19, p:0.015), SF (r:0.30, $\mathrm{p}: 0.0001)$, and $\operatorname{ERD}(\mathrm{r}: 0.27, \mathrm{p}: 0.001)$.

\section{Discussion}

The scores the workers achieved on the HPL scale in the present study have a moderate level compared to the studies conducted in different business fields in our country [15-17]. In other studies from other countries, workers had results similar to the present one [18-20]. Ulutasdemir et al reported that private company workers exhibited a moderate level of healthy life behaviors compared to other people in the society [21]. The highest possible score from the present scales was 208. Since the workers had a mean score of 132 , one could say that they had a moderate score of health life behaviors.

However, there are differences among the studies in terms of the workers' sociodemographic characteristics affecting HPL scale scores. Some studies performed in different business fields showed sociodemographic characteristics affected scale scores [19, 20, 22], whereas others reported no significant differences [15-17, 21, 23]. It has been emphasized in the literature that sex is an effective factor in healthy life behaviors. In the study by Avci et al, although there was no difference between the groups in terms of the education level and marital status, it was shown that the women's scale scores were higher [24]. However, no significant differences were observed among the groups in terms of sex, in the present study. Given that men mainly work in some work fields and women predominantly work in others, it is unlikely that the gender effect may reflect realistic results (the bias error). Although men formed $86 \%$ of the participants in the present study, women accounted for $83 \%$ of the participants in Avcı's study [24].

It has been reported that HPL scale scores increase with an increase in age [8, 24]. In addition, it was observed in this study that the elderly age group had higher scores than other age groups. It could be stated that with an increase in age, due to caring more about health issues, people avoid risky behaviors they show during puberty and youth, and their awareness of healthy lifestyle behaviors increases.

In contrast to the studies conducted using the SF36 scale, the scores in the present study were lower than the one conducted in a Turkish cement factory, in which SF and P scores were the same
[25]. All low scale scores of the workers in this study, excluding that of ELV, were lower than the scores obtained in the study of Demiral et al, which indicates the high level of Turkish society standards [26]. In a similar study, the cleaning workers' life quality was below the Turkish society standards and the present study results [27]. In another study, in contrast, among workers from small companies, it was reported that their life quality levels were higher than those of other people in the society, especially compared to the elderly, because they were younger and had more health potentials, i.e. the healthier worker effect [28]. Against this background, one could conclude that the workers' life quality could be different from that of the general society, which could be below the standards in workers in some business fields.

Based on the results of the present study, one could state that the effect of age on the life quality could not be unidirectional. For example, although the physical area (PF and PRD) scores in the fourth decade of age were found to be low, social functionality scores in this age group were the highest among others. However, it was found out that $\mathrm{MH}$ scores were high among participants in their twenties. The effect of age is negative on all life quality areas in one's old age, during which chronic diseases and physical limitations often occur [29].

There are differences observed in the literature in terms of the effect of sex on the life quality. In some studies, men's total SF-36 subscale scores were found to be lower than women's scores [3031], whereas in another, scores were found to be higher among male workers [28]. In other studies, it was reported that PF and PRD scores were higher in men than in women [32-33]. This finding could be resulted from women's workload, housework, and motherhood responsibilities. In the present study, although sex did not affect the life quality, female workers were less active in the business field we chose; thus, as discussed before, it could have caused an error in the determination of the gender effect.

The results also alluded to other sociodemographic characteristics, such as marital status and the education level, which had no effect on the life quality, having been consistent with other studies $[25,27]$. Nevertheless, it was demonstrated in the present study that the single participants had significantly higher $\mathrm{MH}$ scores, with the same results having been reported by Demirbag et al [25]. The causes of higher mental health levels in the single workers could have been due to having no marriage-related responsibilities, no socioeconomic problems, and no concerns about children. 
It has been shown that behaviors are associated with the health-related quality of life [34-36]. It also seems there is a positive relationship between an increase in healthy lifestyle behaviors and an increase in the life quality [22, 37, 38]. In the present study, it was shown that there was a lower correlation between PF, PRD, SF, and MH scores, which are healthy lifestyle behavior subscales. In addition, it was reported in the study by Gursel et al that there was a moderate positive correlation between HPL scores and PF, PRD, and $\mathrm{MH}$ scores [30]. In the same vein, in a study on factory workers in Japan, it was proved that healthy lifestyle behaviors affected $\mathrm{MH}$ levels [39]. With all these studies considered, one could say that an improvement in healthy lifestyle behaviors could lead to a positive progress in all areas of the quality of life, especially in the physical area among workers.

According to the results, although the workers' healthy lifestyle behaviors were at a moderate level in this study, their health-related quality of life was found to be below the society standards. In addition, the effects of sociodemographic characteristics on healthy lifestyle behaviors and on the quality of life were partial, with healthy lifestyle behaviors having improved the workers' quality of life. In general, educational status, life circumstances, and socio-economic indicators of blue-collar workers are lower than those of other strata of the society. This difference has an effect on the use of healthcare as well [40]. Upon considering characteristics, such as age, sex, and marital status, true healthy behaviors would be reinforced through educating workers, thereby increasing personal and social health levels; accordingly, it would be possible to increase the quality of life among workers, who are an integral part of the society.

It is recommended that the workers' quality of life be investigated in their workplace to identify the major aspects of their lives in terms of the impact on the quality of life and on doing necessary planning.

This study had several limitations. In fact, the cross-sectional design of the study limited the explanation of causal relationships among the variables. Thus, further research is required with a longitudinal experimental design to confirm the determinants of health-promoting behaviors as well as the effects of the health-related quality of life on workers. In this study, data were used based on the employees' self-statements. In addition, the participants were limited to voluntary workers in the central warehouse of a large chain of grocery stores in Samsun province. Thus, further replication of this study is required with different employment areas and occupations.

\section{Conclusion}

According to the results of this study, healthy lifestyle behaviors could improve the quality of life among workers. It is worth noting that many factors could affect the quality of life, with these factors being different in every society and every workplace.

\section{Acknowledgement}

The authors would like to express their sincere gratitude to the participants for their assistance in this study.

Conflict of interest: None declared.

\section{References}

1. Mirghafourvand $M$, Baheiraei A, Nedjat $S$, Mohammadi E, Charandabi SM, Majdzadeh R. A population-based study of health-promoting behaviors and their predictors in Iranian women of reproductive age. Health Promot Int 2015; 30(3):586-94.

2. Glanz K, Bishop DB. The role of behavioral science theory in development and implementation of public health interventions. Annu Rev Public Health 2010; 31:399-418.

3. Esin N. The Turkish version of the HealthPromoting Lifestyle Profile instrument. Nursing Bull. 1999; 12: 87-95.

4. Karaca T, Ozkan SA. Evaluation of healty lifestyle behaviours scale which consist of nursing students and nurses as sample in studies: A review study. Journal of Human Science 2016; 13(2):3588-601

5. Park K, Hwang SY. 10-year risk for cardiovascular disease among male workers in small-sized industries. J Cardiovasc Nurs 2015; 30(3):267-73.

6. Tambag $\mathrm{H}, \mathrm{Oz} \mathrm{F}$. Evaluation of the psychoeducation given to the elderly at nursing homes for a healthy lifestyle and developing life satisfaction. Community Ment Health J 2013; 49(6):742-7.

7. Development of the World Health Organization WHOQOL-BREF quality of life assessment. The WHoQOL Group. Psychol Med 1998; 28(3):5518.

8. Khalili $P$, Vazirinejad $R$, Jamalizadeh $A$, Nakhaee $P$, Fatehi F, Fallah A. The impact of healthy lifestyle education and integrated care on the quality of life of the elderly. Journal of Occupational Health and Epidemiology 2014; 3(2):81-7.

9. Teles MA, Barbosa MR, Vargas AM, Gomes VE, Ferreira EF, Maetins AM, et al. Psychosocial work conditions and quality of life 
among primary health care employees: a cross sectional study. Health Qual Life Outcomes 2014; 12(1):72.

10. van Rijn RM, Robroek SJ, Brouwer S, Burdorf A. Influence of poor health on exit from paid employment: a systematic review. Occup Environ Med 2014; 71(4):295-301.

11. Walker SN, Sechrist KR, Pender NJ. The Health - Promoting Lifestyle Profile: development and psychometric characteristics. Nurs Res 1987; 36(2):76-81.

12. Bahar Z, Beser A, Gordes N, Ersin F, Kıssal A. Healthy Lifestyle Behavior Scale II Validity and Reliability Study. C.U. Cumhuriyet Journal of Nursing 2008; 12(1):1-12.

13. Ware JE Jr, Sherbourne CD. The MOS 36-Item Short-Form Health Survey (SF--36): I. Conceptual Framework and Item Selection. Med Care 1992; 30(6):473-83.

14. Kocyigit $\mathrm{H}$, Aydemir $\mathrm{O}$, Olmez N, Memis A. The reliability and validity of the F-36 for Turkish. Ege Fizik Tedavi ve Rehabilitasyon Derg 1999; 12:102-6.

15. Beser A, Bahar Z, Buyukkaya D. Health promoting behaviors and factors related to lifestyle among Turkish workers and occupational health nurses' responsibilities in their health promoting activities. Ind Health 2007; 45(1):151-9.

16. Karadag G, Kocak HS, Aydın N, Kilic SP, Kul S. Determination of some Nutritional Habits and Healthy Life-Style Behaviours of Workers. International Journal of Caring Sciences 2013; 6(3):485-93.

17. Yilmazel G, Nacar M, Cetinkaya F. Health promotion behaviors of workers working in an industrial establishment. TAF Preventive Medicine Bulletin 2015; 14(2):161-70.

18. Yu K, Bi J, Huang Y, Li F, Cheng J, Wang T, et al. Relationship between health promoting Lifestyle and sub-health status in the employees of an enterprise. Nan Fang Yi Ke Da Xue Xue Bao 2013; 33(8):1203-6.

19. Zhang SC, Wei CN, Fukumoto K, Harada K, Ueda K, Minamoto K, et al. A comparative study of health-promoting lifestyles in agricultural and non-agricultural workers in Japan. Environ Health Prev Med 2011; 16(2):80-9.

20. Huang SL, Li RH, Tang FC. Comparing disparities in the health-promoting lifestyles of Taiwanese workers in various occupations. Ind Health 2010; 48(3):256-64.

21. Ulutasdemir N, Kilic M, Zeki Ö, Begendi F. Effects of Occupational Health and Safety on Healthy Lifestyle Behaviors of Workers Employed in a Private Company in Turkey. Ann Glob Health 2015; 81(4):503-11.

22. Cakir M, Piyal B, Aycan S. Healthy lifestyle behaviors and quality of life in physicians: a faculty of medicine based cross-sectional study Ankara Medical Journal 2015; 15(4):209-19.

23. Gocer S, Polat T, Oral B, Gunay O. Determination of healthy lifestyle behaviors of workers in a factory. In: Public Health Experts Association editors. $18^{\text {th }}$ National Public Health Congress Book. Proceeding of the $18^{\text {th }}$ National Public Health Congress; 2015 Oct 5-9; Konya, Turkey.P.898

24. Avcı IA, Erdogan TK. Hazelnut factory workers in working in the evaluation of the frequency of obesity and healthy life habits. TAF Preventive Medicine Bulletin 2015; 14(5):364-9

25. Demirbag BC, Bayrak B, Özkan ÇG, Çaylak E. Evaluation of the Life Quality of Workers in a Cement Factory. Procedia Soc Behav Sci 2017; 237:1462-7.

26. Demiral Y, Ergor G, Unal B, Semin S, Akvardar $Y$, Kivircik $B$, et al. Normative data and discriminative properties of Short form 36 (SF$36)$ in Turkish urban population. BMC Public Health 2006; 6:247.

27. Namal F, Oysul FG, Ozden A. Assessment of health-related quality of life of personnel performing cleaning work at Gülhane military medical Academy. In: Public Health Experts Association editors. $18^{\text {th }}$ National Public Health Congress Book. Proceeding of the $18^{\text {th }}$ National Public Health Congress; 2015 Oct 5-9; Konya, Turkey. P.911.

28. Uskun E, Oztürk M, Kisioğlu AN, Sonmez Y. Risk factors of small scale work places in an industrial site in relations to quality of life. Turkish Journal of Public Health 2016; 13(2):97114

29. Kucukberber N, Ozdilli K, Yorulmaz $\mathrm{H}$. Evaluation of factors affecting healthy life style behaviors and quality of life in patients with heart disease. Anadolu Kardiyol Derg 2011; 11(7):619-26.

30. Gursel N, Ozbey S, Guzel P. Healthy Lifestyle Behaviors and Life Quality of Instructors. International Journal of Social Science Research 2016: 5(2):10-25.

31. Tsai SY. Health-related quality of life association with work-related stress and social support among female and male disabled employees. Women Health 2016; 56(8):957-76.

32. Kocak FU, Ozkan F. Physical activity levels and the quality of life in the elderly. Turkiye Clinical Journal of Sports Science 2010; 2(1):46-54.

33. Sagıroglu M, Gunay $O$. The effect of cardiovascular risk factors on the quality of life in the patients who applied to the family health center. In: Public Health Experts Association editors. $18^{\text {th }}$ National Public Health Congress Book. Proceeding of the $18^{\text {th }}$ National Public Health Congress; 2015 Oct 5-9; Konya, Turkey. P.456.

34. van Vilsteren $\mathrm{M}$, van Oostrom $\mathrm{SH}$, de Vet $\mathrm{HC}$, Franche RL, Boot CR, Anema JR. Workplace interventions to prevent work disability in workers on sick leave. Cochrane Database Syst Rev 2015; 10:CD006955.

35. Yilmaz F, Caglayan C. The effects of healthy lifestyle on the quality of life among elderly. 
Turkish Journal of Family Practice 2016; 20(4):129-40

36. Chang HT, Liu LF, Chen CK, Hwang SJ, Chen $\mathrm{LK}, \mathrm{Lu} \mathrm{FH}$. Correlates of institutionalized senior veterans' quality of life in Taiwan. Health Qual Life Outcomes 2010; 8:70.

37. Teskereci G, Oncel S. Effect of lifestyle on quality of life of couples receiving infertility treatment. J Sex Marital Ther 2013; 39(6):47692.

38. Rakhshani T, Shojaiezadeh D, Lankarani KB, Rakhshani $\mathrm{F}$, Kaveh $\mathrm{MH}$, Zare $\mathrm{N}$. The association of health-promoting lifestyle with quality of life among the Iranian elderly. Iran
Red Crescent Med J 2014; 16(9):e18404.

39. Suda M, Nakayama K, Morimoto K. Relationship between behavioral lifestyle and mental health status evaluated using the GHQ28 and SDS questionnaires in Japanese factory workers. Ind Health 2007; 45(3):467-73.

40. Ilhan MN, Tuzun H, Aycan S, Aksakal FN, Ozkan S. Health Care Service Use Characteristics of the Primary Health Care Center Attendants and the Variation With Regard to Some Socioeconomic Indicators: Last Determinations before the Health Reform. Bulletin of Community Medicine 2006; 25(3); 33-41. 